\title{
Utilization of cell-transferred cytologic smears in detection of EGFR and KRAS mutation on adenocarcinoma of lung
}

\author{
Howard H Wu, Joseph P Eaton, Kelly J Jones, Harvey M Cramer, Melissa L Randolph, \\ Kristin M Post, Amanda Malek, Sarah Bilbo, Joyashree D Sen, Shaoxiong Chen and \\ Liang Cheng
}

Department of Pathology and Laboratory Medicine, Indiana University School of Medicine, Indianapolis, IN, USA

\begin{abstract}
Cell-transfer technique has been proven useful for performing immunocytochemistry on fine-needle aspiration smears. However, its utility for EGFR and KRAS molecular testing has not been validated. Molecular testing was performed using the cell-transfer technique on both Papanicolaou-stained ethanol-fixed and Hema 3-stained air-dried smears from 32 fine-needle aspiration samples that had diagnoses of adenocarcinoma of the lung, and then was compared to the results of the corresponding formalin-fixed paraffin-embedded tissues. The molecular testing was successfully performed on 32 of 32 ethanol-fixed and 31 of 32 air-dried samples. The molecular results on ethanol-fixed and air-dried smears showed $100 \%$ agreement. There is $100 \%(32 / 32)$ agreement for the EGFR and $97 \%(31 / 32)$ agreement for the KRAS between the cell-transfer technique and formalin-fixed paraffin-embedded tissues. One discrepant case was due to low percentage of tumor cells on the smears. Cell-transfer technique is a reliable alternative method for EGFR and KRAS testing if the cell blocks lack adequate cellularity.
\end{abstract}

Modern Pathology (2014) 27, 930-935; doi:10.1038/modpathol.2013.220; published online 13 December 2013

Keywords: cell transfer; cytology; EGFR; fine-needle aspiration; KRAS

Lung cancer exacts a considerable toll within the United States, each year claiming approximately 160000 lives, a figure that represents more than $25 \%$ of total annual US cancer mortality. ${ }^{1}$ Nonsmall-cell lung cancers, which account for $85 \%$ of all lung cancers, are often diagnosed at an advanced stage and have poor prognosis. ${ }^{2,3}$ Adenocarcinoma represents the most common type of lung cancer, and understanding of its molecular pathogenesis has led to the development of several novel chemotherapeutic agents that offer potentially effective therapy on the basis of targeting specific genetic alterations such as mutations in the epidermal growth factor receptor (EGFR) and the Kristen-Rous sarcoma virus (KRAS). EGFR mutations are found in approximately $10-15 \%$ of non-small-cell lung cancers with the highest frequency occurring in adenocarcinoma. $^{4-8}$ Lung adenocarcinomas driven by

Correspondence: Dr HH Wu, MD, Department of Pathology and Laboratory Medicine, Indiana University School of Medicine350 W. $11^{\text {th }}$ Street, IUHPL-4086, Indianapolis, IN 46202, USA.

E-mail: hhwu@iupui.edu

Received 29 August 2013; accepted 6 October 2013; published online 13 December 2013
EGFR mutations are sensitive to tyrosine kinase inhibitors such as gefitinib and erlotinib, and these patients will have longer progression-free survival than the patients whose tumors do not contain EGFR mutations. ${ }^{9-12}$ KRAS represents a downstream effector of $E G F R$ and lung adenocarcinomas with $K R A S$ mutations are refractory to EGFR tyrosine kinase inhibitors. The occurrence of EGFR and KRAS mutations is mutually exclusive; hence performing both markers at the same time also serves an important quality control function. ${ }^{13-16}$ Performing molecular testing on newly diagnosed advanced staged non-small-cell lung cancers in a timely fashion has become the standard of care. ${ }^{17}$

Fine-needle aspiration is a safe, minimally invasive and relatively inexpensive diagnostic method, which may be used for the evaluation of both primary and metastatic lung cancer. ${ }^{18}$ Although a diagnosis can often be made primarily based on cytomorphologic features, the utilization of formalinfixed paraffin-embedded cell blocks prepared from fine-needle aspiration specimens is also considered a reliable source of tumor cells for the assessment of molecular abnormalities. ${ }^{19}$ Cell blocks, however, sometimes lack adequate cellularity even in the 
face of highly cellular aspirate smears. The use of direct cytologic smears as a resource for molecular testing has been described in several publications using a variety of different methods. ${ }^{20-22}$ The celltransfer technique has proven to be a reliable and useful method in our institution for performing immunocytochemistry using direct cytologic smears as a source of tumor cells when the cell block lacks adequate cellularity. ${ }^{23,24}$ We therefore set out to establish the cell-transfer technique as a viable option for isolating tumor cells for subsequent EGFR and KRAS mutation analysis via the currently used polymerase chain reaction (PCR)-based platforms. To validate this technique, we tested corresponding formalin-fixed paraffin-embedded tissue in addition to the direct smears including both ethanol-fixed and air-dried smears for comparison.

\section{Materials and methods}

This study was approved by the Institutional Review Board of Indiana University (Protocol number 1205008629). A computerized search of the anatomic pathology information system was performed. Fine-needle aspiration cases diagnosed as primary or metastatic adenocarcinoma of the lung, which had corresponding formalin-fixed paraffinembedded tissues, were identified over a 48-month period. The search yielded a total of 32 fine-needle aspiration specimens. The formalin-fixed paraffinembedded tissues included 20 lobectomy specimens, 2 biopsies, and 10 cell blocks. The Papanicolaoustained ethanol-fixed and Protol Hema 3-stained (Fisher Scientific, Kalamazoo, MI) air-dried direct smears from each case as well as the corresponding hematoxylin and eosin-stained slides from the corresponding formalin-fixed paraffin-embedded tissues were reviewed. One ethanol-fixed, one air-dried direct smear slide, and one representative formalin-fixed paraffin-embedded block containing tumor cells were selected for molecular testing. The areas on the direct smears containing tumor cells were marked by a pathologist and photographs were taken from these areas. Both EGFR and KRAS mutational studies were performed on cells obtained from ethanol-fixed, air-dried, and formalin-fixed paraffin-embedded samples of each case. The amount of DNA from each sample was quantitated. The number of tumor cells and the percentage of tumor cells were also documented.

\section{Cell-Transfer Technique}

The cell-transfer technique was performed using clean technique as follows: (1) the coverslip was removed using fresh histologic grade xylene (Fisher Scientific, Pittsburgh, PA, USA); (2) a thin layer of Mount Quick media (Daido Sangyo, Tokyo, Japan) was spread uniformly over the top of the cellular material; (3) the slide was then placed in a $60{ }^{\circ} \mathrm{C}$ heated oven for approximately $2-3 \mathrm{~h}$ (or until hardened to the touch); (4) a Sharpie marker was used on the surface of the dried media to divide the slide into multiple areas of interest; (5) the slide was then placed into a clean Coplin jar of deionized water and submerged into a warm water bath at $45 \pm 3{ }^{\circ} \mathrm{C}$ for $30 \mathrm{~min}$ to $2 \mathrm{~h}$, or until the media was soft enough to easily peel away from the slide; and (6) the media was cut along the marked areas, and each cut section was placed in an Eppendorf $2.0 \mathrm{ml}$ safe-lock centrifuge tube and sent for molecular testing.

\section{DNA Extraction}

DNA extraction from formalin-fixed paraffinembedded tissue and cytologic specimens was performed using the Qiagen QIAamp DNA Formalinfixed Paraffin-embedded Tissue Kit (Qiagen, Valencia, CA, USA). A modification from the manufacturer's recommendations was made. Samples were incubated at room temperature for $5 \mathrm{~min}$ with $1 \mathrm{ml}$ of xylene and were then centrifuged at 15000 r.p.m. for 5 min. Xylene was removed from the pellet and ethanol wash was then performed as recommended by the manufacturer. DNA concentration was determined using the NanoDrop Spectrophotometer.

\section{EGFR}

After DNA concentration was measured, the DNA was adjusted to approximately $10 \mathrm{ng} / \mu \mathrm{l}$ in distilled water. For EGFR mutational analysis, PCR amplified products were analyzed on the Q24 Pyrosequencer with Qiagen EGFR Pyro kits (Qiagen). The pyrosequencing kit tests for mutations in the exon 18 codon 719 region, deletions in exon 19, mutations in the exon 20 codon 768 and codon 790 regions, and mutations in exon 21 codon regions 858 through 861. The resulting amplicons were purified, denatured, and sequenced using mutation adjacent primers. Pyrograms were generated by the software and interpreted for the presence of mutations in the corresponding codons.

\section{KRAS}

Samples were run using the Qiagen therascreen KRAS RGQ PCR on the Rotor-Gene Q MDx following the manufacturer's recommendations. Genomic DNA was used to detect seven somatic mutations in codons 12 and 13 of the KRAS oncogene using real-time PCR on the Rotor-Gene Q instrument using both Scorpions and Amplification Refractory Mutation System technologies (Qiagen). ${ }^{25-27}$ The somatic mutations capable of being detected were 12ALA, 12ASP, 12ARG, 12CYS, 12SER, 12VAL, and 13ASP. The reaction mixes were duplex, containing reagents labeled with FAM to detect mutant targets and HEX to detect the internal control. Overall, this 
is a two-step procedure with the first step being a control assay to assess the total DNA content in a sample and the second step being both the mutation and control assays to determine the presence or absence of mutated DNA. The threshold at which the signal is detected above background signaling is called the cycle threshold. Sample delta cycle threshold values are calculated as the difference between the mutation assay cycle threshold and wild-type assay cycle threshold from the same sample. Samples are subsequently classified as mutation positive if they give a delta cycle threshold less than the stated cutoff value for the assay and above this value the sample is not detected. The data were analyzed using Rotor-Gene Q series software. Appropriate positive and negative controls were run with each sample.

The mutant allele frequencies of the EGFR base substitutions ranged from 0.6 to $10.7 \%$ (EGFR Pyro Handbook, Qiagen; September 2010; http://www. qiagen.com/knowledge-and-support). The mutant allele frequencies of the KRAS base substitutions ranged from $0.8 \%$ to $6.4 \%$ (therascreen KRAS RGQ PCR Kit, Instructions for Use (Handbook). QIAGEN. July 2012; http://www.qiagen.com/knowledge-andsupport).

\section{Results}

There were 32 fine-needle aspiration specimens from 32 patients identified including 11 males and 21 females, age 36-84 years with an average of 64 years. All the cytological samples obtained using the cell-transfer technique contained more than 50-tumor cells with greater than $90 \%$ of cells being tumor cells, except for two cases: Case 1 (30-50 tumor cells, $75 \%)$ and Case $22(<30$ tumor cells, $<10 \%)$. The DNA yield ranged from $0.2-77.8 \mu \mathrm{g}$ (median, $2.8 \mu \mathrm{g}$ ) for ethanol-fixed and $0.8-60.2 \mu \mathrm{g}$ (median $3.6 \mu \mathrm{g}$ ) for air-dried cytological samples (Table 1). In 32 of $32(100 \%)$ ethanol-fixed and 31 of $32(97 \%)$ air-dried cytologic samples, both EGFR and KRAS tests were successfully performed (Table 2). For KRAS, 15 mutations and 16 wild types, negative for mutation, showed correlation between the cytologic specimens using the celltransfer technique and the formalin-fixed paraffinembedded tissues. In one case, the formalin-fixed paraffin-embedded tissues showed KRAS mutations whereas the cell-transfer technique demonstrated wild-type result. Re-reviewing the original direct smears from this case (Case 22) showed only scant tumors cells $(<10 \%)$ present in a background of

Table 1 Clinical data of EGFR mutational analysis on cytologic smears and formalin-fixed paraffin-embedded

\begin{tabular}{|c|c|c|c|c|c|c|c|c|}
\hline Case no. & Age & Sex & FNA site & Histology site & Tumor cell no. & $\%$ Tumor cells & $D N A-E F$ (ng) & $D N A-A D$ (ng) \\
\hline 1 & 53 & $\mathrm{~F}$ & Lung RLL & Lobectomy & $30-50$ & $50-90 \%$ & 10.4 & 7.6 \\
\hline 2 & 81 & $\mathrm{M}$ & Lung RML & Lobectomy & $>50$ & $>90$ & 2.1 & 3.7 \\
\hline 3 & 41 & $\mathrm{~F}$ & Lung LLL & Lobectomy & $>50$ & $>90$ & 3.5 & 3.6 \\
\hline 4 & 57 & $\mathrm{~F}$ & Lung LUL & Lobectomy & $>50$ & $>90$ & 2.5 & 0.9 \\
\hline 5 & 69 & $\mathrm{~F}$ & Lung LUL & Lobectomy & $>50$ & $>90$ & 7.5 & 1.4 \\
\hline 6 & 64 & $\mathrm{~F}$ & Lung RUL & Lobectomy & $>50$ & $>90$ & 2.7 & 2.5 \\
\hline 7 & 62 & $\mathrm{~F}$ & Lung LLL & Lobectomy & $>50$ & $>90$ & 24.4 & 1.5 \\
\hline 8 & 73 & $\mathrm{~F}$ & Lung LLL & Lobectomy & $>50$ & $>90$ & 0.2 & 0.8 \\
\hline 9 & 83 & $\mathrm{~F}$ & Lung LUL & Lobectomy & $>50$ & $>90$ & 4.1 & 3.7 \\
\hline 10 & 53 & $\mathrm{~F}$ & Lung RLL & Lobectomy & $>50$ & $>90$ & 3.7 & 7.3 \\
\hline 11 & 52 & $\mathrm{~F}$ & Lung RUL & Lobectomy & $>50$ & $>90$ & 1.8 & 8.5 \\
\hline 12 & 69 & $\mathrm{M}$ & Lung RLL & Lobectomy & $>50$ & $>90$ & 2.8 & 2.1 \\
\hline 13 & 68 & $\mathrm{M}$ & Lung RUL & Lobectomy & $>50$ & $>90$ & 1.3 & 2.2 \\
\hline 14 & 62 & $\mathrm{~F}$ & Lung RUL & Lobectomy & $>50$ & $>90$ & 1.8 & 9.7 \\
\hline 15 & 84 & $\mathrm{~F}$ & Lung LUL & Lobectomy & $>50$ & $>90$ & 4.7 & 3.7 \\
\hline 16 & 73 & $\mathrm{~F}$ & Lung RLL & Lobectomy & $>50$ & $>90$ & 3.9 & 4.4 \\
\hline 17 & 54 & $\mathrm{~F}$ & Lung LLL & Lobectomy & $>50$ & $>90$ & 0.9 & 2.6 \\
\hline 18 & 56 & M & Lung RUL & Lobectomy & $>50$ & $>90$ & 4.6 & 4.7 \\
\hline 19 & 59 & $\mathrm{~F}$ & Lung RUL & Lobectomy & $>50$ & $>90$ & 1.1 & 4.7 \\
\hline 20 & 76 & M & Lung LUL & Lobectomy & $>50$ & $>90$ & 0.4 & 1.3 \\
\hline 21 & 36 & $\mathrm{M}$ & Lung RML & Biopsy & $>50$ & $>90$ & 0.4 & 8.7 \\
\hline 22 & 56 & $\mathrm{~F}$ & Lung hilar & Biopsy & $<30$ & $<10$ & 12.9 & 3.4 \\
\hline 23 & 53 & $\mathrm{M}$ & Lung RLL & FNA cell block & $>50$ & $>90$ & 1.9 & 1.8 \\
\hline 24 & 74 & M & Lung RUL & FNA cell block & $>50$ & $>90$ & 1.4 & 5.2 \\
\hline 25 & 45 & M & LN subcarinal & FNA cell block & $>50$ & $>90$ & 44.7 & 5.5 \\
\hline 26 & 84 & $\mathrm{~F}$ & Lung LLL & FNA cell block & $>50$ & $>90$ & 4.4 & 1.2 \\
\hline 27 & 67 & $\mathrm{~F}$ & Lung RLL & FNA cell block & $>50$ & $>90$ & 3.8 & 1.2 \\
\hline 28 & 54 & $\mathrm{~F}$ & LN subcarinal & FNA cell block & $>50$ & $>90$ & 2.4 & 0.8 \\
\hline 29 & 62 & $\mathrm{~F}$ & Lung RUL & FNA cell block & $>50$ & $>90$ & 14.8 & 19.7 \\
\hline 30 & 59 & $\mathrm{~F}$ & LN subcarinal & FNA cell block & $>50$ & $>90$ & 26 & 7.1 \\
\hline 31 & 64 & $\mathrm{M}$ & Lung RUL & FNA cell block & $>50$ & $>90$ & 1.9 & 2.8 \\
\hline 32 & 65 & $\mathrm{M}$ & Lung RLL & FNA cell block & $>50$ & $>90$ & 77.8 & 60.2 \\
\hline
\end{tabular}

Abbreviations: AD, air-dried cytologic samples; EF, ethanol-fixed cytologic samples; F, female; FNA, fine-needle aspirate; LLL, left lower lobe; LML, left middle lobe; ; LN, lymph node; LUL, left upper lobe; M, male; RLL, right lower lobe; RML, right middle lobe; RUL, right upper lobe. 
Table 2 Mutational results on correlated formalin-fixed paraffinembedded tissue and cytology smears

\begin{tabular}{|c|c|c|c|c|c|c|}
\hline $\begin{array}{l}\text { Case } \\
\text { no. }\end{array}$ & $\begin{array}{c}E G F R \\
(F F P E)\end{array}$ & $\begin{array}{c}E G F R \\
(E F)\end{array}$ & $\begin{array}{c}E G F R \\
(A D)\end{array}$ & $\begin{array}{l}\text { KRAS } \\
\text { (FFPE) }\end{array}$ & $\begin{array}{c}\text { KRAS } \\
(E F)\end{array}$ & $\begin{array}{c}\text { KRAS } \\
(A D)\end{array}$ \\
\hline 1 & L858R & L858R & L858R & Neg & Neg & Neg \\
\hline 2 & Neg & Neg & Neg & G12S & G12S & G12S \\
\hline 3 & Neg & Neg & Neg & Neg & Neg & Neg \\
\hline 4 & Neg & Neg & Failed & G12V & G12V & Failed \\
\hline 5 & Neg & Neg & Neg & G12C & G12C & G12C \\
\hline 6 & Neg & Neg & Neg & Neg & Neg & Neg \\
\hline 7 & Neg & Neg & Neg & $\mathrm{G} 12 \mathrm{C}$ & G12C & G12C \\
\hline 8 & Neg & Neg & Neg & Neg & Neg & Neg \\
\hline 9 & Neg & Neg & Neg & G12D & G12D & G12D \\
\hline 10 & Neg & Neg & Neg & Neg & Neg & Neg \\
\hline 11 & Neg & Neg & Neg & G12A & G12A & G12A \\
\hline 12 & Neg & Neg & Neg & Neg & Neg & Neg \\
\hline 13 & Neg & $\mathrm{Neg}$ & Neg & G12D & G12D & G12D \\
\hline 14 & Neg & Neg & Neg & G12V & G12V & G12V \\
\hline 15 & Neg & Neg & Neg & G12C & G12C & G12C \\
\hline 16 & Neg & Neg & Neg & G12V & G12V & G12V \\
\hline 17 & Neg & Neg & Neg & Neg & Neg & Neg \\
\hline 18 & Neg & Neg & Neg & Neg & Neg & Neg \\
\hline 19 & $\mathrm{Neg}$ & Neg & Neg & Neg & $\mathrm{Neg}$ & Neg \\
\hline 20 & Neg & Neg & Neg & Neg & Neg & Neg \\
\hline 21 & Neg & Neg & Neg & Neg & Neg & Neg \\
\hline 22 & Neg & Neg & Neg & G12R & Neg & Neg \\
\hline 23 & 19 del & 19 del & $19 \mathrm{del}$ & Neg & Neg & Neg \\
\hline 24 & 19 del & 19 del & 19 del & Neg & Neg & Neg \\
\hline 25 & Neg & Neg & Neg & $\mathrm{G} 12 \mathrm{C}$ & G12C & G12C \\
\hline 26 & Neg & Neg & Neg & Neg & Neg & Neg \\
\hline 27 & Neg & Neg & Neg & $\mathrm{G} 12 \mathrm{C}$ & $\mathrm{G} 12 \mathrm{C}$ & G12C \\
\hline 28 & Neg & Neg & Neg & Neg & Neg & Neg \\
\hline 29 & Neg & Neg & Neg & G12A & G12A & G12A \\
\hline 30 & Neg & Neg & Neg & G12C & G12C & G12C \\
\hline 31 & Neg & $\mathrm{Neg}$ & Neg & G12C & G12C & G12C \\
\hline 32 & Neg & Neg & Neg & Neg & Neg & Neg \\
\hline
\end{tabular}

Abbreviations: AD, air-dried smears; EF, ethanol-fixed smears; FFPE, formalin-fixed paraffin-embedded tissue; Neg, negative.

abundant benign bronchial cells. For EGFR, 3 mutations and 29 wild types showed complete agreement between the cell-transfer technique and the formalin-fixed paraffin-embedded technique (Table 2). When the molecular tests were successfully performed, the cell-transfer technique showed $100 \%$ agreement between ethanol-fixed and airdried cytologic specimens. Correlation between the molecular analysis on the cell-transfer technique and the corresponding formalin-fixed paraffinembedded resection specimen revealed a positive correlation in 15/16 KRAS and 3/3 EGFR cases and a negative correlation in 16/16 KRAS and 29/29 EGFR cases with a sensitivity rate of $95 \%$ and specificity rate of $100 \%$.

\section{Discussion}

The cell-transfer technique is a feasible method for obtaining cellular material from fine-needle aspiration direct smears for immunocytochemical stains. ${ }^{23}$ In this study, we also confirmed its utility to yield an adequate quantity of DNA from tumor cells for the molecular testing to identify EGFR and KRAS mutations. There is high agreement rate (97\%) between the fine-needle aspiration smears using the cell-transfer technique and the formalin-fixed paraffin-embedded tissue. The selection of adequately cellular areas with tumor cells is very important for assessing the correct mutational status. The one case we encountered with discordant cell-transfer technique and formalin-fixed paraffin-embedded results (Case 22), which can be explained by inadequate tumor quantity on the direct smears. Upon re-review of the photographs taken before the cell transfer, only rare malignant cells could be identified on both wet-fixed and air-dried slides. An overabundance of benign bronchial epithelial contaminant was noted in the background, most likely the source of the spurious wild-type karyotype, whereas abundant tumor in the formalin-fixed paraffin-embedded sample provided an adequate sample for detecting the G12R mutation. Excluding this case, the agreement reached $100 \%$ between the cell-transfer technique and the gold standard formalin-fixed paraffin-embedded. At least 30 tumor cells and greater than $50 \%$ of the cells submitted being tumor cells are required for the adequate materials for the molecular testing in order to prevent a false negative result. ${ }^{17}$ All the cases in our study that met the above criteria showed $100 \%$ agreement with the corresponding formalin-fixed paraffin-embedded tissues. The higher the number of tumor cells the more accurate molecular results can be achieved. For the cases with greater than $50 \%$ of tumor cells, the sensitivity to identify mutations is $100 \%$ for both air-dried and ethanol-fixed smears. Both air-dried and ethanol-fixed smears also showed $100 \%$ correlation with the formalin-fixed paraffinembedded cell block tissue in 10 cases. Additional study needs to be done to see how sensitive this assay can be. For clinical practice, we will perform the assay even if the concentration of tumor cells is less than $50 \%$; however, a comment regarding the sensitivity issue will be added for the negative results. The ability to visualize and select the tumor cells through the cell-transfer technique provides an advantage over the recut of the formalin-fixed paraffin-embedded tissue, especially when the tumor cells are fewer and the surrounding normal tissues are abundant in the block, factors that may cause a false-negative result for the formalin-fixed paraffin-embedded tissue. Both air-dried and ethanolfixed direct smears are useful as the resource for the molecular testing as long as they are adequately cellular. In one of the 32 cases (Case 4), the air-dried smears failed to perform the molecular testing through the cell-transfer technique. However, for the rest of the 31 cases in our study, both ethanolfixed and air-dried smears show 100\% agreement between these two methods for the EGFR and KRAS mutational results.

The cell-transfer technique is a very useful method for obtaining cellular material for immunostaining 
and molecular testing if the conventionally prepared cell blocks lack adequate cellularity. Technically, the processing steps are not complex and either a histology or cytology technologist can easily be trained to perform the procedure. Cell transfer can be performed in any laboratory and no special equipment is necessary. Furthermore, the additional cost is relatively low and multiple immunostains as well as multiple molecular mutational tests can be performed from a single cellular smear using the cell-transfer technique. The cost of the MountQuik is approximately $\$ 20.00$ per tube, which can be used for 30-50 cases and the cost of scalpel blades, pipette and slides are minimal. After the selected areas have been removed, the rest of the smears can be re-coverslipped and kept in the file for future review.

In this study, the strong correlation between molecular assays performed on fine-needle aspiration material by utilizing the cell-transfer technique, and molecular assays performed on traditional unstained recut sections from formalin-fixed paraffin-embedded tissue samples indicate that the celltransferred cytologic smears are a reliable alternative resource for assessing EGFR and KRAS mutations of both the primary and metastatic non-small cell carcinoma of the lung. The limitations of this study are retrospective, single center study, and small numbers of the cases. A larger scale, prospective, multi-institutional study is needed for further validation of this novel, cost-effective cell-transfer technique for molecular testing on the cytologic smears

\section{Acknowledgments}

This study was supported by the Department of Pathology of Laboratory Medicine, Indiana University School of Medicine, Indianapolis, Indiana.

\section{Disclosure/conflict of interest}

The authors declare no conflict of interest.

\section{References}

1 Siegel R, Naishadham D, Jemal A. Cancer statistics, 2013. CA Cancer J Clin 2013;63:11-30.

2 Parkin M, Tyczynski JE, Boffetta P, et al. Lung cancer epidemiology and etiology, In: Travis WD, Brambilla E, Müller-Hermelink HK, et al. (eds). WHO Classification of Tumours: Pathology and Genetics of Tumours of the Lung, Pleura, Thymus and Heart. IARC Press: Lyon, France; 2004, pp 12-25.

3 Fathi AT, Brahmer JR. Chemotherapy for advanced stage non-small cell lung cancer. Semin Thorac Cardiovasc Surg 2008;20:210-216.

4 Ladanyi M, Pao W. Lung adenocarcinoma: guiding EGFR targeted therapy and beyond. Mod Pathol 2008;21(suppl 2):S16-S22.
5 Suda K, Tomizawa K, Mitsudomi T. Biological and clinical significance of KRAS mutations in lung cancer: an oncogenic driver that contrasts with EGFR mutation. Cancer Metastasis Rev 2010;29: 49-60.

6 Sharma SV, Bell DW, Settleman J, et al. Epidermal growth factor receptor mutations in lung cancer. Nat Rev Cancer 2007;7:169-181.

7 Mitsudomi T, Yatabe Y. Mutations of the epidermal growth factor receptor gene and related genes as determinants of epidermal growth factor receptor tyrosine kinase inhibitors sensitivity in lung cancer. Cancer Sci 2007;98:1817-1824.

8 Lynch TJ, Bell DW, Sordella R, et al. Activating mutations in the epidermal growth factor receptor underlying responsiveness of non-small-cell lung cancer to gefitinib. N Engl J Med 2004;350: 2129-2139.

9 Paez JG, Janne PA, Lee JC, et al. EGFR mutations in lung cancer: correlation with clinical response to gefitinib therapy. Science 2004;304:1497-1500.

10 Pao W, Miller V, Zakowski M, et al. EGF receptor gene mutations are common in lung cancers from 'never smokers' and are associated with sensitivity of tumors to gefitinib and erlotinib. Proc Natl Acad Sci USA 2004;101:13306-13311.

11 Mitsudomi T, Kosaka T, Endoh H, et al. Mutations of the epidermal growth factor receptor gene predict prolonged survival after gefitinib treatment in patients with non-small cell lung cancer with postoperative recurrence. J Clin Oncol 2005;23:2513-2520.

12 Takano T, Fukui T, Ohe Y, et al. EGFR mutations predict survival benefit from gefitinib in patients with advanced lung adenocarcinoma: a historical comparison of patients treated before and after gefitinib approval in Japan. J Clin Oncol 2008;26:5589-5595.

13 Rodenhuis S, van de Wetering ML, Mooi WJ, et al. Mutational activation of the K-ras oncogene: a possible pathogenetic factor in adenocarcinoma of the lung. N Engl J Med 1987;317:929-935.

14 Kim YT, Kim TY, Lee DS, et al. Molecular changes of epidermal growth factor receptor (EGFR) and KRAS and their impact on the clinical outcomes in surgically resected adenocarcinoma of the lung. Lung Cancer 2008;59:111-118.

15 van Zandwijk N, Mathy A, Boerrigter L, et al. EGFR and KRAS mutations as criteria for treatment with tyrosine kinase inhibitors: retro- and prospective observations in non-small cell lung cancer. Ann Oncol 2007;18:99-103.

16 Eberhard DA, Johnson BE, Amler LC, et al. Mutations in the epidermal growth factor receptor and in KRAS are predictive and prognostic indicators in patients with non-small-cell lung cancer treated with chemotherapy alone and in combination with erlotinib. J Clin Oncol 2005;23:5900-5909.

17 Lindeman NI, Cagle PT, Beasley MB, et al. Molecular testing guideline for selection of lung cancer patients for EGFR and ALK tyrosine kinase inhibitors: guideline from the College of American Pathologists, International Association for the Study of Lung Cancer, and Association for Molecular Pathology. Arch Pathol Lab Med 2013;137:828-860.

18 Adams J, Wu HH. The utility of fine-needle aspiration in the diagnosis of primary and metastatic tumors to the lung: a retrospective examination of 1032 cases. Acta Cytologica 2012;56:590-595. 
19 Smouse JH, Cibas ES, Janne PA, et al. EGFR mutations are detected comparably in cytologic and surgical pathology specimens of nonsmall cell lung cancer. Cancer (Cancer Cytopathol) 2009;117:67-72.

20 Betz BL, Roh MH, Weigelin HC, et al. The application of molecular diagnostic studies interrogating EGFR and KRAS mutations to stained cytologic smears of lung carcinoma. Am J Clin Pathol 2011;136:564-571.

21 Billah S, Stewart J, Staerkel G, et al. EGFR and KRAS mutations in lung carcinoma. Cancer (Cancer Cytopathol) 2011;119:111-117.

22 Santos GDC, Saieg MA, Geddie W, et al. EGFR gene status in cytological samples of nonsmall cell lung carcinoma. Cancer (Cancer Cytopathol) 2011;119:80-91.

$23 \mathrm{Wu} \mathrm{HH}$, Jones KJ, Cramer HM. Immunocytochemistry performed on the cell-transferred direct smears of the fine-needle aspirates. Am J Clin Pathol 2013;139: $754-758$.
24 Ferguson J, Chamberlain P, Cramer HM, et al. ER, PR, and HER2 immunocytochemistry on cell-transferred cytologic smears of primary and metastatic breast carcinomas: a comparison study with formalin-fixed cell blocks and surgical biopsies. Diagn Cytopathol 2013;41:575-581.

25 Harbison CT, Horak CE, Ledeine JM, et al. Validation of companion diagnostic for detection of mutations in codons 12 and 13 of the KRAS gene in patients with metastatic colorectal cancer: analysis of the NCIC CTG CO.17 trial. Arch Pathol Lab Med 2013;137: 820-827.

26 Whitcombe D, Theaker J, Guy SP, et al. Detection of PCR products using self-probing amplicons and fluorescence. Nat Biotechnol 1999;17:804-807.

27 Thelwell N, Millington S, Solinas A, et al. Mode of action and application of Scorpion primers to mutation detection. Nucleic Acids Res 2000;28:3752-3761. 